\title{
Molecular Cloning and Expression Analysis of a MADS-Box Gene (GbMADS2) from Ginkgo biloba
}

\author{
Xiaohui $\mathrm{WANG}^{1}$, Junhuan $\mathrm{CHENG}^{1}$, Feng XU ${ }^{1 *}$, Xingxiang $\mathrm{LI}^{2}$, Weiwei ZHANG ${ }^{1}$, \\ Yongling $\mathrm{LIAO}^{3}$, Shuiyuan $\mathrm{CHENG}^{4}$, Xianbin $\mathrm{LI}^{5}$ \\ ${ }^{1}$ College of Horticulture and Gardening, Yangtze University, Jingzhou, 434023, \\ China; 529179525@qq.com;374334033@qq.com;xufeng198@126.com (*orrespondingauthor);wwzhangchn@163.com \\ ${ }^{2}$ Medical School, Yangtze University, Jingzhou, 434023, China; lxx@yangtzeu.edu.cn \\ ${ }^{3}$ College of Forestry, Nanjing Forest University, Nanjing, 210037, China; liaoyongling@yeah.net \\ ${ }^{4}$ Wuhan Polytechnic University, Wuhan 430023, China;s_y_cheng@sina.com \\ Singzhou Soil and Fertilizer Station, Jingzhou 434025, China; 676593359@qq.com
}

\begin{abstract}
As a kind of transcription factors gene family, MADS-box genes play an important role in plant development processes. To find genes involved in the floral transition of Ginkgo biloba, a MADS-box gene, designated as GbMADS2, was cloned from G. biloba based on EST sequences by RT-PCR. Sequence analysis results showed that the cDNA sequence of GbMADS2 contained a 663 bp length ORF encoding 221 amino acids protein, which displayed typical structure of plant MADS-box protein including MADS, I, and $\mathrm{K}$ domains and $\mathrm{C}$ terminus. The sequence of GbMADS2 protein was highly homologous to those of MADS-box proteins from other plant species with the highest homologous to AGAMOUS (CyAG) from Cycas revoluta. The phylogenetic tree analysis revealed that GbMADS2 belonged to AGAMOUS clade genes. Real-time PCR analysis indicated that expression levels of GbMADS2 gene in female and male flower were significantly higher than those in root, stem, and leaves, and that GBMADS2 expression level increased along with time of flower development. The spatial and timecourse expression profile of GbMADS2 implied that GbMADS2 might be involved in development of reproductive organs. The isolation and expression analysis of GbMADS2 provided basis for further studying the molecular mechanism of flower development in G. biloba.
\end{abstract}

Keywords: bioinformatics analysis, GbMADS2, spatial expression pattern, time-course expression pattern

\section{Introduction}

Plant flower formation and development is a complex process that is controlled by environmental and endogenous signals (Brambilla and Fornara, 2013), with four main pathways: autonomous, photoperiod, vernalization, and gibberellin-mediated (Bernier and Périlleux, 2005). Many genes involved in flower development act in concert with physiological signals to establish complex gene regulatory networks that regulate flowering and floral organ development. Many of these genes belong to the MADS-box gene family, which is a large transcription factor family with diverse roles, especially floral development (Hemming and Trevaskis, 2011). Also, MADS genes are great significant for studying the system evolution of plant groups because of their universality and highly conservatism in the plant kingdom (Purugganan et al., 1995). In flowering plants, MADS-box genes control diverse developmental processes in organs ranging from roots to flowers and fruit development $(\mathrm{Ng}$ and
Yanofsky, 2001). In regard to biological metabolism, researcher have found an important function of MADS which as transcription factors regulate the biosynthetic pathways of secondary metabolites flavonoids (Lalusin et al., 2006). Moreover, MADS-box genes involve in plant growth and development process, such as synthesis of gibberellin (Jackson, 2009), the fruits ripening (Ireland et al., 2013), plant dormancy (Saito et al., 2013), the root elongation (Zhang and Forde, 1998), callus differentiation (Fornara $e t$ al., 2004), shoot development (Lee et al., 2008).

Ginkgo biloba, the only surviving genus and species of the Ginkgoaceae family, is a dioecious tree, native of China. Resistant to city smoke and industrial fumes, it has become a favorite ornamental tree in parks and streets of numerous towns all over the world. Moreover, G. biloba accumulates, mainly in its leaves, two types of compounds of pharmaceutical importance, that are terpenes (ginkgolides

Received: 12 Dec 2014. Received in revised form: 22 Apr 2015. Accepted: 14 May 2015. Published online: 17 May 2015. 
20

and bilobalide) and flavonoids. The leaf extracts are widely used for the treatment of peripheral or cerebral circulatory disorders, especially in geriatric practice (Van Beek and Montoro, 2009). G. biloba is a kind of Mesozoic precious plants with a special long juvenile phase, general 15 to 20 years to bear fruit after planting. As a unique relict species belonging to a plant lineage known as Ginkgophyta, $G$. biloba has many unique flowering habits compared with other plants (Chen et al., 2008). Therefore, it is important theoretical and practical significance to study floral organ development and fruit formation on $G$. biloba. However, up to now, little literature reported isolation and function of the genes involved in $G$. biloba flower organ development. To explore the molecular mechanism of $G$. biloba flower organ development, this study isolated a MADS-box gene, designated as $G b M A D S 2$, from $G$. biloba and analyzed the gene expression patterns in different $G$. biloba organs. This work aimed to provide the theoretical basis for further studies on the molecular mechanism of this gene participating in flowering in G. biloba.

\section{Materials and methods}

\section{Plant materials}

15-year-old grafts of $G$. biloba were grown in a greenhouse at Yangtze University, China. To test the spatial expression pattern of GbMADS2, the roots, leaves, fruits, stems, male and female flowers of $G$. biloba grafts were collected. For measurement of the time-course expression patter of GbMADS2 in ginkgo flowers, the male and female flower samples on 2, 4, 6, 8, and 10 days after flower bud sprouting. All the samples were collected and immediately frozen in liquid nitrogen, and kept at $-80^{\circ} \mathrm{C}$ prior to total RNA extraction.

\section{Cloning of the full-length cDNA of GbMADS2}

Total RNA was extracted from female flowers using the CTAB method (Cai et al., 2007). The quality and concentration of the RNA was all determined by agarose gel electrophoresis and spectrophotometer analysis. The primers MADSFP (5'TGCTCTAAATTCCAACAGAAAAG-3') and MADSRP (5'-GTAATATATCCCGCCCATAAACT-3') were designed and synthesized (Shanghai Sangon, China) based on the EST sequence of $G$. biloba. A 712 bp-length fragment was obtained using the one-step RT-PCR kit (Dalian TaKaRa, China) under the following conditions: $50^{\circ} \mathrm{C}$ for $30 \mathrm{~min}$ and $94^{\circ} \mathrm{C}$ for $3 \mathrm{~min}$, followed by 35 cycles of amplification at $94^{\circ} \mathrm{C}$ for $1 \mathrm{~min}, 51^{\circ} \mathrm{C}$ for $1 \mathrm{~min}$, and $72^{\circ} \mathrm{C}$ for $1 \mathrm{~min}$. The PCR product was purified, cloned into the pMD18-T vector (Dalian TaKaRa, China), and then sequenced. Subsequent BLAST results confirmed that the amplified product was the sequence of the MADS gene.

\section{Bioinformatics analysis and molecular evolution analyses}

The obtained nucleotide sequence and deduced amino acid sequence were compared through database search using BLAST program (NCBI, http://www.ncbi.nlm.nih.gov). Multiple sequence alignment was performed with the software Vector NTI suit 10.0 program. The protein sequences of GbMADS2 and other MADSs were obtained from GenBank and aligned with the software Vector NTI suit 10.0 program. Phylogenetic tree was constructed using CLUSTAL W 1.83 and MEGA 4.0. The reliability of the tree was measured by bootstrap analysis with 100 replicates.

\section{Quantitative Real Time-PCR analysis of GbMADS2}

To investigate expression pattern of GbMADS2 gene in different tissues, total RNA of the roots, leaves, fruits, stems, male and female flowers of $G$. biloba were isolated. First-strand cDNA synthesis was carried out in triplicate for each sample according to the instructions of the manufacturer (Real-Time PCR Reagent Kit, Dalian TaKaRa, China). Quantitative Real-time PCR (qRTPCR) was performed using a Perkin-Elmer 7000 thermal cycler with SYBR Premix Ex Taq ${ }^{\text {Ti }}$ II Kit (Dalian TaKaRa, China) according to the protocol of the manufacturer. Reactions were performed in triplicate using $2 \mu \mathrm{L}$ of Master Mix, $0.5 \mathrm{M}$ of each primer, $2 \mu \mathrm{L}$ of diluted cDNA template, and nuclease free water to a final volume of $20 \mu \mathrm{L}$. The PCR reaction conditions were $95^{\circ} \mathrm{C}$ for $3 \mathrm{~min}$, and then 30 cycles of $94^{\circ} \mathrm{C}$ for $1 \mathrm{~min}, 60^{\circ} \mathrm{C}$ for $30 \mathrm{~s}$, and $72{ }^{\circ} \mathrm{C}$ for $30 \mathrm{~s}$, with a final extension at $72{ }^{\circ} \mathrm{C}$ for $3 \mathrm{~min}$. Fluorescence was measured at the end of each annealing step. Raw data were analyzed with Light Cycler software, and expression level was normalized to $G$. biloba house-keeping gene $18 S$ (Gb18S, GenBank accession no. D16448) to minimize the variation in the cDNA template levels. The primers for GbMADS2 gene (MADS2S: 5'-GTGGCTCTCATCGTCTTCTC-3'; MADS2-A: 5'ATTTGCTGTCTCAGTTTTCC-3') and Gb18S gene (18S-S: 5'-ATAACAATACTGGGCTCATCG-3'; 18S-A: 5'TTCGCAGTGGTTCGTCT'TC-3') were designed using the Sequence Detection System software. Real-time PCR data were technically replicated with error bars, representing mean $\pm S E(n=3)$.

\section{Results}

\section{Cloning and characterization of GbMADS2}

The amplified products of RT-PCR were separated on $1 \%$ agarose gel stained with ethidium bromide. The result showed that the PCR products size was about 700 bp (Fig. 1), which had a same size with the expected MADS-box gene sequence. The recyclable PCR products were sequenced, and showed that the cDNA sequence of PCR products contained $712 \mathrm{bp}$. The results of BlastN analysis on NCBI showed that this cDNA sequence had high similarity with that of other MADS genes. The nucleotide sequence of GbMADS2 was $84 \%$ and $80 \%$ identical to MADS-box gene from Cycas edentata and Rafflesia cantleyi, and $82 \%, 82 \%$, and $81 \%$ identical to $A G A M O U S$ gene from Macrozamia spiralis Ceratozamia mexicana, Zamia integrifolia, and $74 \%$ identical to AGAMOUS-like gene from Magnolia denudata, respectively (Table 1), indicating the gene we isolated

Table 1. Nudeotide sequence of GbMADS2 similarity to the MADS-box genes from other plant species

\begin{tabular}{lccc}
\hline Species & GeneID & $\begin{array}{c}\text { GenBank } \\
\text { AccessionNo. }\end{array}$ & Homology \\
\hline Cycasedentata & MADS-box & AF492455 & $84 \%$ \\
Macrozamiaspiralis & $A G$ & HM596862 & $82 \%$ \\
Ceratozamiamexicana & $A G$ & HM596861 & $82 \%$ \\
Zamia integrifolia & $A G$ & HM596866 & $81 \%$ \\
Rafflesia cantleyi & MADS-box & KF730033 & $80 \%$ \\
Magnoliadenudata & AGAMOUS-like & JQ326231 & $74 \%$ \\
\hline
\end{tabular}


is a member of MADS-box gene family. Therefore, this gene was designated as GbMADS2 (GenBank Accession No. KP260628). As shown in Fig. 2, the nucleotide sequence of $G b M A D S 2$ gene contained a 663 bp length open reading frame (ORF), encoding a predicted protein sequence of 221 amino acid residues. Furthermore, the homologous sequence of MADS genes among different species showed that GbMADS2 gene might keep a strong conserved role during the molecular evolution (Smaczniak et al., 2012).

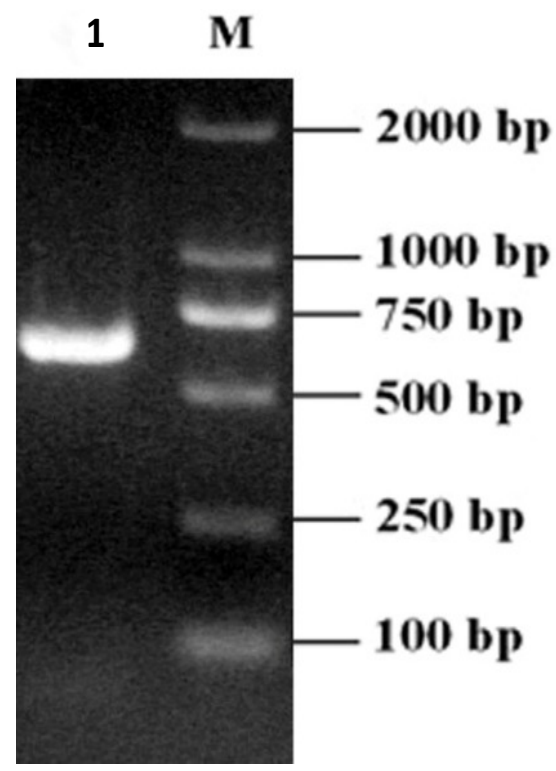

Fig. 1. Elecrtophoresis pattern of amplified product of GbMADS2 from Ginkgo biloba. 1 - Amplified products of GbMADS2 cDNA ; M DNA Marker DL2000

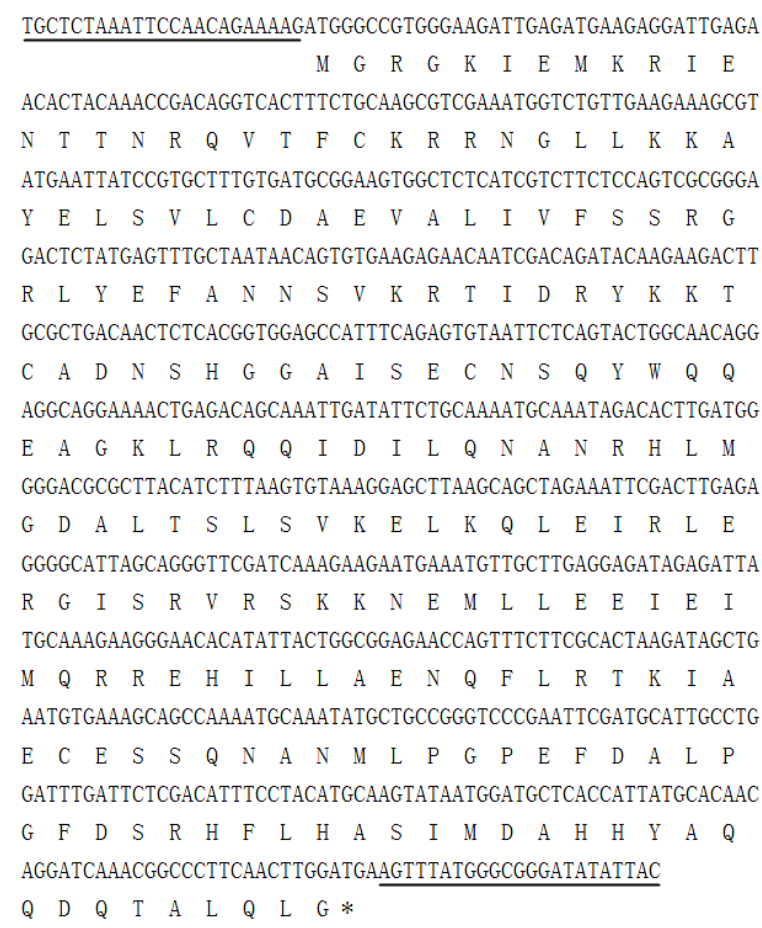

Fig. 2. The nucleotide acid sequence and deduced amino acid sequence of GbMADS2. The underline for specific primers MADSFP and MADSRP
Characterization of the deduced G6MADS2 protein

The deduced GbMADS2 had high similarities with other plant MADS-box proteins by using DNAMAN 6.0. It was found that GbMADS2 exhibited 91\% identity with AGAMOUS (CyAG) from Cycas revolute, 83.7\% identity with DAL2 from Picea abies and 61.4\% identity to AGL11 from Arabidopsis thaliana, respectively (Fig. 3). BlastP analysis showed that GbMADS2 possessed typical MADSbox protein structure of MIKC type (type II) plants.

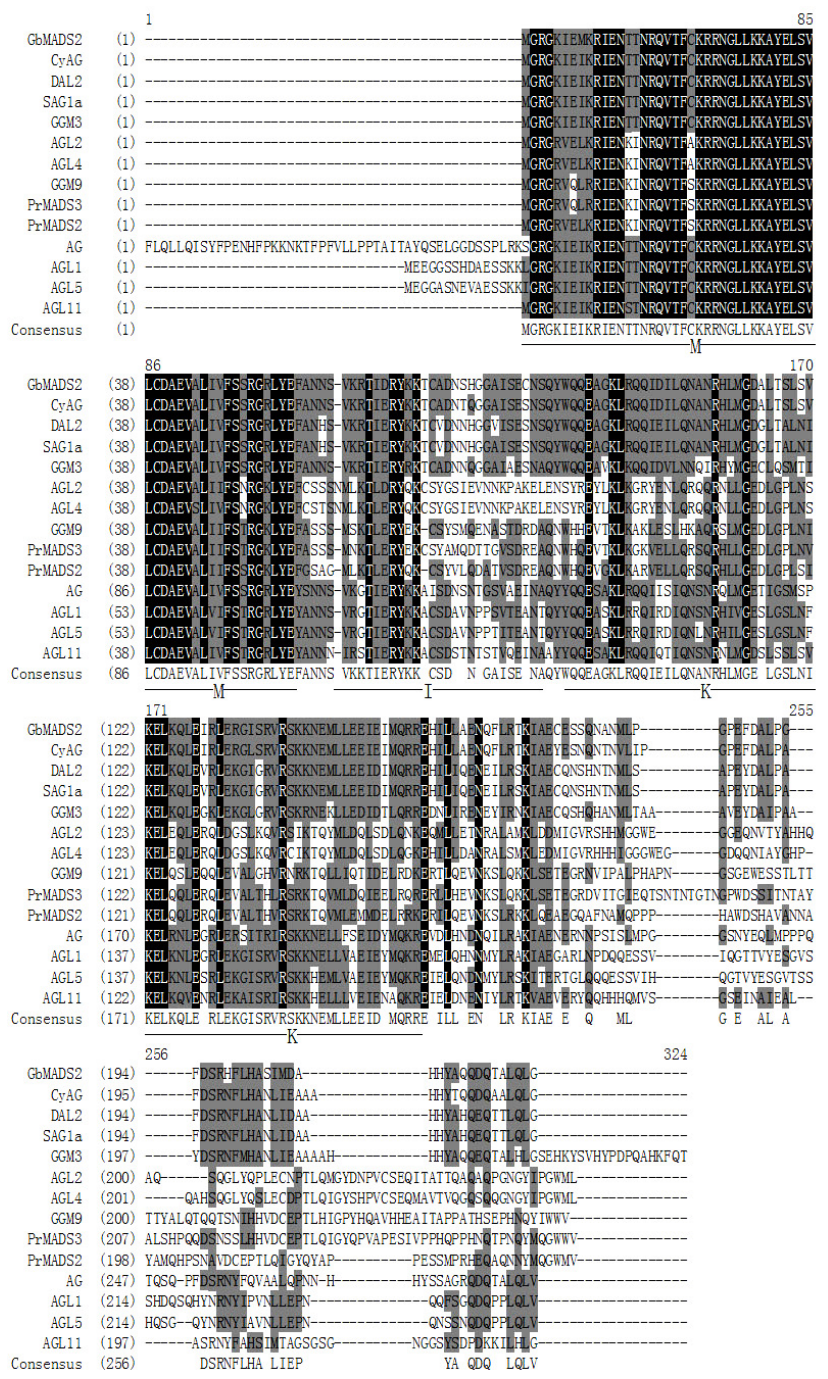

Fig. 3. The homologue comparison of GbMADS2 amino acid sequence with other MADS-box protein. The completely identical amino acids are indicated with white foreground and black background. The conserved amino acids are indicated with black foreground and grey background. Nonsimilar amino acids are indicated with black foreground and white background. The specie and protein name and GenBank accession number are as following: Ginkgo biloba: GbMADS2 (AKE50811); Arabidopsis thaliana: AG (CAB78898), AGL1 (M55550), AGL5 (M55553), AGL2 (M55551), AGL4 (M55552) and AGL11 (U20182); Cycas revolute: CyAG (AF492455); Picea abies: DAL2 (X79280); Picea mariana: SAG1a (U69482); Gnetum gnemon: GGM3 (AJ132209) and GGM9 (AJ132215); Pinus radiata: PrMADS2 (U42400) and PrMADS3 (U76726) 
22

According to the modular domain structure of type II MADS protein, GbMADS2 could be divided into four conservative domains (Fig. 3), including MADS domain at 157 amino acids, $\mathrm{K}$ domain at 91-156 amino acids, I domain containing 33 amino acids, and a $\mathrm{C}$ terminus. However, GbMADS2 did not show high homology with the sequence of $\mathrm{N}$-terminus extension of AG proteins of Arabidopsis thaliana, but similar to the AG subfamily of reported MADS-box protein from other plants. Compared the different domains similarities of GbMADS2 with CyAG, DAL2 and AGL11, respectively, they had the highest homology in MADS domain. It was found that GbMADS2 exhibited $94.74 \%, 100 \%$, and $100 \%$ similarities in MADS domain as well as $8.5 \%, 86.4 \%$ and $69.7 \%$ similarities in $\mathrm{K}$ domain of CyAG, DAL2 and AGL11, respectively (Fig. 3).

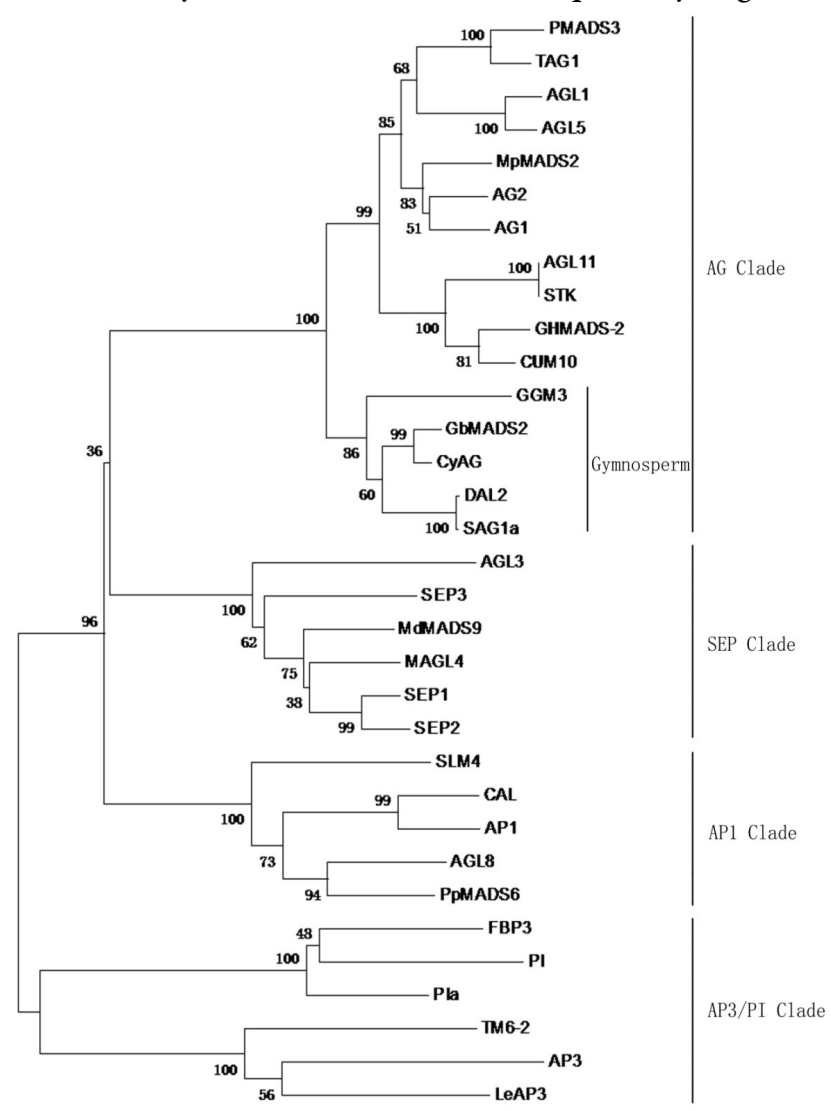

0.1

Fig. 4. Phylogenetic tree analysis of protein encoded by MADS-box genes. The specie and protein name and GenBank accession number are as following: Arabidopsis thaliana: STK (NP_001078364), CAL (NP_564243), AP1 (CAA78909), AGL8 (Q42429), AGL3 (P29383), SEP1(P29382), SEP2 (P29384), SEP3 (O22456), PI (NP_197524) and AP3 (NP_191002); Petunia hybrida: PMADS3 (BAB79434) and FBP3 (CAA50549); Lycopersicon esculentum: TAG1 (Q40168) and LeAP3 (AAC42583); Eschscholzia californica: AG2 (AAZ53206) and AG1 (AAZ53205); Magnolia praecocissima: MpMADS2 (BAB70737); Gossypium hirsutum: GHMADS-2 (AAN15183); Cucumis sativus: CUM10 (AAC08529); Prunus persica: PpMADS6 (AAU29514); Malus domestica: MdMADS9 (CAA04920); Populus tremuloides: MAGL4 (AAL08423); Lotus corniculatus var. japonicus: PIa (AAX13299); Carica papaya: TM6-2(ABQ51322); Silene latifolia: SLM4(CAA56658)

\section{Molecular evolution analysis}

To investigate the evolutionary relationships in GbMADS2 and MADSs from other plant species, we choose some typical MADS-box genes from GenBank to analyze molecular evolution of GbMADS2 on the basis of the four subfamilies (AP1, AP3/PI, SEP and AG) of flowers homologous alien genes of MADS-box gene. A phylogenetic tree was constructed by using NJ method of MEGA software. As shown in Fig. 4, GbMADS2 belonged to the subfamily of AG genes in the branch of AP1, AP3/PI, SEP, AG, and had the closest relationship with $\mathrm{CyAG}$ of $C$. revolute. Taken into account together with high sequence homologies of GbMADS2 with other plant AG protein, our data suggested that GbMADS2 belonged to AG subfamily of MADS-box gene families. These results suggested that GbMADS2 shared a common evolutionary with other plant AG proteins based on conserved structure and sequence characteristics, such as amino acid homologies and conserved motifs, respectively.

\section{Expression analysis of G6MADS2}

To investigate the expression of GbMADS2 gene in different tissues of $G$. biloba, qRT-PCR was carried out using gene-specific primers and cDNAs from different ginkgo tissues as templates. As shown in Fig. 5, GbMADS2 was strongly expressed in male and female flowers, but negligible amounts of its transcripts were detected in roots, stems, and leaves vegetative tissues of $G$. biloba. For further examine the role of $G b M A D S 2$ during flower development, we measured the time-course expression pattern of $G b M A D S 2$ in flowers.

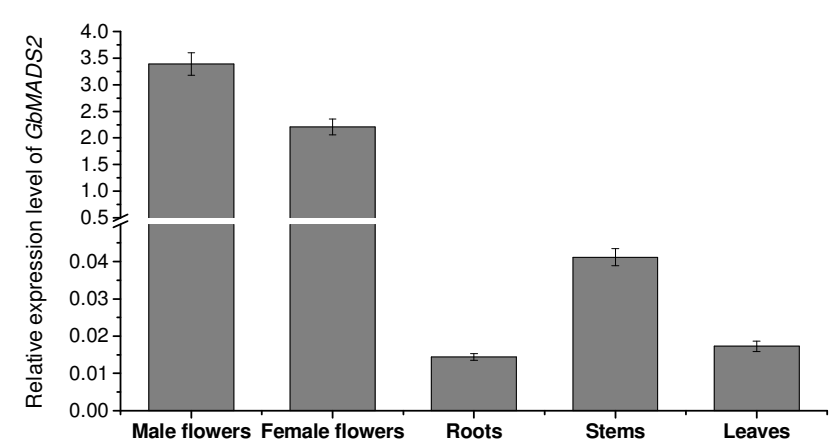

Fig. 5. Expression level of GbMADS2 in different tissue of Ginkgo biloba

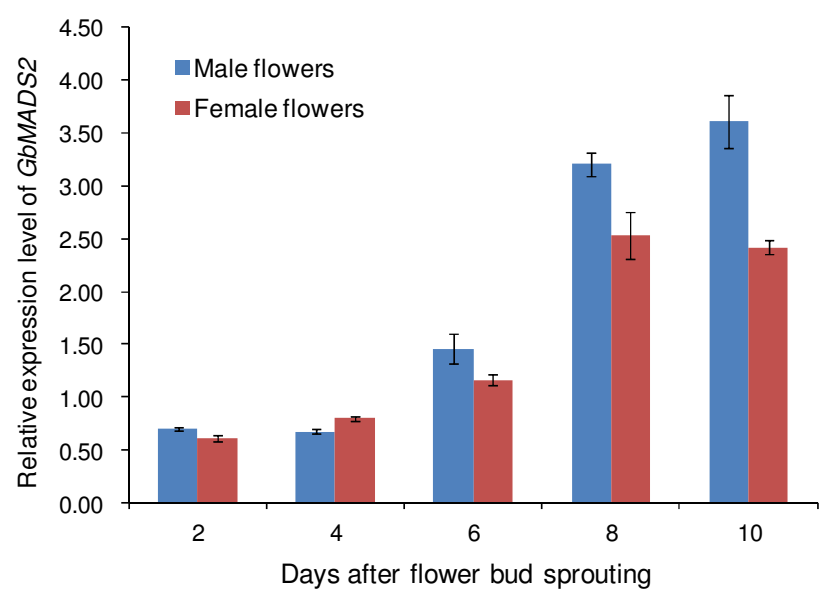

Fig. 6. Time-course expression profile of GbMADS2 during flower development in Ginkgo biloba 
The results showed that the transcript level of GbMADS2 significantly increased along with the development of male and female flowers (Fig. 6), implying that GbMADS2 might be involved in flower development.

\section{Discussions}

MADS-box genes have been divided in two large groups, termed type I and type II genes (Alvarez-Buylla et al., 2000). Type I and type II MADS-box genes were generated by a gene duplication that occurred before the divergence of plants, animals and fungi more than a billion years ago (Becker $e t$ al., 2000). In plants, the type I MADS-box genes function are still not clear, type II MADS-box genes which include all plant MADS-box genes for which expression patterns or mutant phenotypes are known (De Bodt et al., 2003; Kaufmann et al., 2005). The type I MADS-box genes only contain MADS domain-box structure (Nam et al., 2004), while Type II genes comprise MADS-box, I, K and C structure with different degree of conservative, and called MIKC-type MADS-box (Ma et al., 1991; Münster et al., 1997; Nam et al., 2004; Kaufmann et al., 2005). The sequence analysis results revealed that GbMADS2 contained $\mathrm{M}$, I, and $\mathrm{K}$ domains and $\mathrm{C}$ terminus, which are typical MADS-box structure of plants. Therefore, GbMADS2 belongs to MIKC type MADS-box gene and might be related to floral organ formation and development (Coen and Meyerowitz 1991; Heijmans et al., 2012).

Most genomes of plants exist in varying quantity of MADS-box genes duplication. Therefore, it is possible for providing the raw materials for the evolution of the organism new form by gene duplication and function diversification. MADS-box genes form a multiple gene families at many genes duplication of the evolution process, especially in angiosperms (Aswath and Kim, 2005). By phylogeny reconstruction, almost all of the angiosperm MADS-box genes can be subdivided into 12 major gene clades (Becker and Theißen, 2003). Phylogenetic tree showed that gymnosperms and angiosperms had seven same subfamilies of MADS domain, that was to say the existing seed plants have at least seven different MIKC type genes: AG, AGL2, AGL6, DEF/GLO, GGM13, STMADS11 and TM3 gene subfamily in their common ancestor (Smaczniak et al., 2012). Most of MIKC type MADS genes are involved in the development of sporophyte reproductive organs, such as the ovule (Busi et al., 2003). The phylogenetic tree analysis revealed that GbMADS2 gene belonged to AG subfamily, implying that the function of GbMADS2 is probably similar to $A G$ clade genes.

Real-time PCR results revealed that expression level of GbMADS2 in reproductive was significantly higher than that in vegetative tissues, similar to the Arabidopsis and cotton AG genes (Mizukami et al., 1992; Liu et al., 2010), indicating GbMADS2 might play a role in the development of reproductive tissues in $G$. biloba. Similar to the time-course expression profile of OsMADS1 gene in rice (Jeon $e$ al., 2000), we also found the expression level of GbMADS2 exhibited an increased tendency during flower development, further confirming GbMADS2 contribute to flower development in G. biloba. Taken together, the sequence analysis and the expression pattern data supports the conclusion that GbMADS2 probably represents a function orthologue of the AG gene family, implicating that the gene may participate in flower development.

\section{Conclusions}

In summary, isolation and characterization of GbMADS2 gene constitute a start point for our studies of flower development in G. biloba. We have also recently isolated several MADS-box genes of G. biloba and characterized their expression (manuscript in submission). Experiments are underway to further characterize the possible specific role of each gene in G. biloba that will enable us to infer a flower development model of this plant and define ways to enhance its productivity exploiting molecular genetic techniques.

\section{Acknowledgements}

This work was supported by the Youth Talent Foundation of Hubei Province (2013CFA039), the Key Scientific Research Program of Chinese Ministry of Education (212112 and 210137), International Science and Technology Cooperation Project of Hubei Province (2013BHE029 and 2013BHE039), and the Graduate Innovative Project of Jiangsu Province (2013CXZZ13D551).

\section{References}

Alvarez-Buylla ER, Liljegren SJ, Pelaz S, Gold SE, Burgeff C, Ditta GS, Francisco Vergara-Silva F, Yanofsky MF (2000). MADSbox gene evolution beyond flowers: expression in pollen, endosperm, guard cells, roots and trichomes. Plant J $24(4): 457-466$.

Aswath CR, Kim SH (2005). Another story of MADS - box genes - their potential in plant biotechnology. Plant Growth Regul 46(2):177-188.

Becker A, Winter KU, Meyer B, Saedler H, Theißen G (2000). MADS-box gene diversity in seed plants 300 million years ago. Mol Biol Evol 17(10):1425-1434.

Becker A, Theißen G (2003). The major clades of MADS-box genes and their role in the development and evolution of flowering plants. Mol Phylogenet Evol 29(3):464-489.

Bernier G, Périlleux C (2005). A physiological overview of the genetics of flowering time control. Plant Biotechnol J 3(1):316.

Brambilla V, Fornara $F$ (2013). Molecular control of flowering in response to day length in rice. J Integr Plant Biol 55(5):410418.

Busi MV, Bustamante C, D’Angelo C, Hidalgo-Cuevas M, Boggio SB, Valle EM, Zabaleta E (2003). MADS-box genes expressed during tomato seed and fruit development. Plant Mol Biol 52(4):801-815.

Cai R, Xu F, Chen L, Cheng S (2007). Modification of total RNA isolation method from different Ginkgo biloba organs. Biotechnology 17(4):38-41. (In Chinese with English abstract)

Chen L, Cai R, Xu F, Cheng S (2008). Plants flowering gene regulation and Ginkgo juvenile phase genetic improvement research progress. Henan Agric Sci 2:13-16 (In Chinese with English abstract). 
24

Coen ES, Meyerowitz EM (1991). The war of the whorls: genetic interactions controlling flower development. Nature 353(6339):31-37.

De Bodt S, Raes J, Florquin K, Rombauts S, Rouze P, Theiben G, Van de Peer Y (2003). Genome-wide structural annotation and evolutionary analysis of the type I MADS-box genes in plants. Mol Evol 56(5):573-586.

Fornara F, Parenicová L, Falasca G, Pelucchi N, Masiero S, Ciannamea S, Lopez-Dee Z, Altamura MM, Colombo L, Kater MM (2004). Functional characterization of OsMADS18, a member of the AP1/SQUA subfamily of MADS box genes. Plant Physiol 135(4):2207-2219.

Heijmans K, Morel P, Vandenbussche M (2012). MADS-box genes and floral development: The dark side. J Exp Bot 63(15):5397-5404.

Hemming MN, Trevaskis B (2011). Make hay when the sun shines: The role of MADS-box genes in temperature dependant seasonal flowering responses. Plant Sci 180(3):447453.

Ireland HS, Yao JL, Tomes S, Sutherland PW, Nieuwenhuizen N, Gunaseelan K, Winz RA, David KM, Schaffer RJ (2013). Apple SEPALLATA1/2-like genes control fruit flesh development and ripening. Plant J 73(6):1044-1056.

Jackson SD (2009). Plant responses to photoperiod. New Phytol 181(3):517-531.

Jeon JS, Jang S, Lee S, Nam J, Kim C, Lee SH, Chung YY, Kim SR, Lee YH, Cho YG, An G (2000). "leafy hull sterile1" is a homeotic mutation in a rice MADS box gene affecting rice flower development. Plant Cell 12(6):871-884.

Kaufmann K, Melzer R, Theißen G (2005). MIKC-type MADSdomain proteins: structural modularity, protein interactions and network evolution in land plants. Genes 347(2):183-198.

Lalusin, AG, Nishita K, Kim SH, Ohta M, Fujimura, T. (2006). A new MADS-box gene (IbMADS10) from sweet potato (Ipomoea batatas (L.) Lam) is involved in the accumulation of anthocyanin. Mol Genet Genomics 275(1):44-54.

Lee S, Woo YM, Ryu S (2008). Further characterization of a rice AGL12 group MADS-box gene, OsMADS26. Plant Physiol 147(1):1156-168.

Liu X, Zuo K, Xu J, Li Y, Zhang F, Yao H, Wang Y, Chen Y, Qiu C, Sun X, Tang K (2010). Functional analysis of GbAGL1, a D-lineage gene from cotton (Gossypium barbadense). J Exp Bot 61(4):1193-1203.
Ma H, Yanofsky MF, Meyerowitz EM (1991). AGL1-AGL6, an Arabidopsis gene family with similarity to floral homeotic and transcription factor genes. Genes Dev 5(3):484-495.

Mizukami Y, Ma H (1992). Ectopic expression of the floral homeotic gene AGAMOUS in transgenic Arabidopsis plants alters floral organ identity. Cell 71(1):119-131.

Münster T, Pahnke J, Di Rosa A, Kim JT, Martin W, Saedler H, Theissen G (1997). Floral homeotic genes were recruited from homologous MADS-box genes preexisting in the common ancestor of ferns and seed plants. Proc Natl Acad Sci USA 94(6):2415-2420.

Nam J, Kim J, Lee S, An G, Ma H, Nei M (2004). Type I MADSbox genes have experienced faster birth-and-death evolution than type II MADS-box genes in angiosperms. Proc Natl Acad Sci USA 101(7):1910-1915.

$\mathrm{Ng}$ M, Yanofsky MF (2001). Function and evolution of the plant MADS-box gene family. Nature Rev Genet 2(3):186-195.

Purugganan MD, Rounsley SD, Schmidt RJ, Yanofsky MF (1995). Molecular evolution of flower development: diversification of the plant MADS-box regulatory gene family. Genetics 140(1):345-356.

Saito T, Bai S, Ito A, Sakamoto D, Saito T, Ubi BE, Imai T, Moriguchi T (2013). Expression and genomic structure of the dormancy-associated MADS box genes MADS13 in Japanese pears (Pyrus pyrifolia Nakai) that differ in their chilling requirement for endodormancy release. Tree Physiol 33(6):654-667.

Smaczniak C, Immink RG, Angenent GC, Kaufmann K (2012). Developmental and evolutionary diversity of plant MADSdomain factors: insights from recent studies. Development 139(17):3081-3098.

Van Beek T, Montoro P (2009). Chemical analysis and quality control of Ginkgo biloba leaves, extracts, and phytopharmaceuticals. J Chromatogr A 1216(11):2002-2032.

Zhang H, Forde BG (1998). An Arabidopsis MADS box gene that controls nutrient-induced changes in root architecture. Science 279:407-409. 